\title{
Not just words
}

\section{Increasing climate science literacy through clear communication will not be sufficient to maximize public engagement in the climate change debate.}

Journalists in the general media, the writers of popular science articles and those that prepare press releases on which their stories are based are regularly accused by scientists - all too often with good reason - of 'dumbing down', oversimplifying or even misrepresenting the science. Those accused could, with good justification, counter that scientists are guilty of habitually using technical jargon that can do more to obscure than to illuminate meaning to the public.

Certainly, climate science has its fair share of terms likely to cause confusion - 'drivers' (of changes in the climate), 'forcing' (factors, such as volcanism, that affect the climate), 'aerosols' (microscopic particles suspended in the atmosphere), insolation (the energy of the Sun received by the Earth) and 'sink' (for carbon) come immediately to mind. Although technical terms have their place in the scientific literature, it seems obvious that arcane terminology should be avoided when trying to explain climate science to a broader audience: there is nothing 'dumber' than trying to communicate with people using words that they are not going to understand or, worse still, are likely to misconstrue. Scientists in turn rightly insist that, while a degree of simplification is no doubt necessary, scientific accuracy must not be compromised.

Arguably, there is no field of science where clarity of communication is more important than that of climate change. Scientists need to explain in plain, straightforward language the nature of the evidence that the climate is changing, what the probable causes are and what the consequences for society are likely to be. They also need to be upfront regarding gaps in knowledge about how the climate system works, and how uncertainties affect projections of future climate and the confidence that we can have in them. This is not just because the general public want to know, but also because politicians - often with no or limited scientific training must have a clear understanding of the issues if they are to formulate and set in place effective policies to tackle climate change and minimize its societal and environmental impacts.

The public understanding of climate change is in this regard equally crucial: politicians, as servants of the people, cannot work in a vacuum or (in the case of democracies) without the support of those who elect them. However, on page 743 of this issue, Adam Corner and Christopher Groves argue that "a 'deadlock' prevails because of a fundamental tension between the norms of scientific practice and those that govern the social space in which debate about climate change occurs". They further argue that presenting the science clearly and concisely will not in itself break the deadlock and that a new and radically different approach is needed. According to their analysis, what is required is the establishment of new societal institutions where, in their words, "the science and politics of climate change can coexist". Such institutions should, they argue, draw on the findings of social scientists that widespread scepticism about climate change is explained, at least in part, by peoples' strong attachment to "deeply held values and views about the organization of society and political ideology".

But precisely what kind of institutions do they have in mind, and how easy would they be to get up and running? What they seem to envisage are not, or at least not necessarily, the kinds of physical institution that we are familiar with, such as the Grantham Institute in London, the main mission of which is to foster climate change research and to translate this into real world impact by communicating knowledge to help shape decision-making (www3.imperial.ac.uk/grantham). Rather, they appear to favour the establishment of venues, events or partnerships - formal or otherwise - where debate can "accommodate and ease the normative tensions within climate change communication" and that "provide a buffer between the science of climate change and the complex challenge of engaging the public". The purpose of such 'hybrid' institutions, they say, would be to "catalyse new conversations about climate change".

In a related article (page 745), Chris Rapley and Kris De Meyer expand on the theme of the perceived gap between the current role of the climate science community and the needs of society, and discuss how this gap affects the public discourse and the formulation of climate change policy. They call for a sea change in how climate scientists are trained and how they conduct their business, despite the burden of the many responsibilities that researchers already carry. In the foreword of a recent report entitled Time for Change? Climate Science Reconsidered (http://go.nature.com/vaXROL), Rapley, who had a career as a space scientist and is a former director of the London Science Museum, admits that, like many scientists, he finds it a challenge to move away from the conventional 'scientific' way of expressing his thoughts. Nevertheless, he is convinced that climate scientists now need to be equipped with skills that would allow them to contribute effectively to public policy and communicate their findings to a wide and sometimes hostile audience. The report itself calls for the establishment of a professional body tasked with identifying and establishing professional norms, values and practices appropriate to societal needs.

To some readers, Corner and Groves' call for new 'institutions' may seem a bit woolly, at least at first glance. However, they note that similar approaches have been successfully applied in the health domain, in relation to smoking and healthy eating, for example. They also point to initiatives such as World Wide Views (www.wwviews.org), which allowed hundreds of people to express their views ahead of the climate change negotiations in Copenhagen in 2009 and thus become more engaged with the climate debate.

This is somewhat reminiscent of a Commentary published in this journal last October (Nature Clim. Change 3, 850-851; 2013), in which Jeremy Brecher and Kevin Fisher explain how the climate change community might learn from the HIV/AIDS movement. In particular, they highlighted the success of the International AIDS Conference, the most recent of which took place in July 2014 in Melbourne, Australia (www.aids2014.org), in "forging a powerful global movement of scientists, non-governmental organizations and civil society". Of course, the climate change community is not in quite the same place as the AIDS community is now very few people still question the cause of AIDS (the HIV infection), let alone the devastating impact that the disease has had on communities and individual lives. In contrast, many people doubt that climate change is anything other than a natural phenomenon, rather than - as believed by most climate scientists - a potentially irreversible experiment with the planet. 